Review

\title{
Osteopontin -- a promising biomarker for cancer therapy
}

\author{
Ran Wei, Janet Pik Ching Wong, Hang Fai Kwok ${ }^{\bowtie}$ \\ Faculty of Health Sciences, University of Macau, Avenida de Universidade, Taipa, Macau \\ $\square$ Corresponding author: Email: hfkwok@umac.mo; Tel.: +853-8822-4991 \\ ( ) Ivyspring International Publisher. This is an open access article distributed under the terms of the Creative Commons Attribution (CC BY-NC) license \\ (https://creativecommons.org/licenses/by-nc/4.0/). See http://ivyspring.com/terms for full terms and conditions.
}

Received: 2017.04.09; Accepted: 2017.06.04; Published: 2017.07.15

\begin{abstract}
Osteopontin (OPN), a multifunctional protein, has emerged as a potentially valuable biomarker for diagnosing and treating cancers. Recent research focuses on its involvement in tumor biology including the cell proliferation, survival, angiogenesis, invasion, and metastasis. Understanding the molecular mechanisms and pharmacological effects of OPN in cancer development could lead to new targets for improving cancer diagnosis and treatment.

This review explains how the structurally conserved domains of OPN are associated with OPN signaling mediators and CD44, and how the conserved OPN domains determine biological functions. The authors have reviewed representative works of OPN expression in breast cancer and colorectal cancer to elucidate the relationship between OPN and cancer/tumor biology. It has also been shown that the prognostic sensitivity in non-small cell lung cancer, hepatocellular carcinoma, gastric cancer, and ovarian cancer improved compared to the individual marker when OPN was analyzed in conjunction with other markers. The therapeutic approaches based on OPN inhibitors are discussed to illustrate recent research progress. Previous clinical data has indicated that OPN has played a unique role in cancer development, but further investigation is required to understand the underlying mechanism. More clinical trials are also required to examine the applicability and efficacy of OPN inhibitors in cancer therapy.
\end{abstract}

Key words: Angiogenesis, Biomarker, Osteopontin, Therapeutic target, Tumor biology

\section{Introduction}

Osteopontin (OPN) was a combined word consisting of "osteo" and "pontin", which was typically named to characterize its linkage role of bone cells to the bone extracellular [1]. OPN is a 34 $\mathrm{kDa}$ acidic glycoprotein; after it is secreted from the cell, it undergoes post-translational modifications giving a resultant molecular size of $44 \mathrm{kDa}$ to $75 \mathrm{kDa}$ in different mammalian cells. OPN was first recognized as a secreted phosphoprotein 1 (SPP1) in 1979 [2], also known as Early T-lymphocyte Activation 1 (ETA1) protein, and Bone Sialoprotein 1 (BSP1) [3]. Currently, OPN has been classified as the Small Integrin-Binding Ligand N-linked Glycoprotein (SIBLING) family. Moreover, OPN is highly expressed in osteoblasts and osteoclasts with an important role in biomineralization [4], and it also participates in various physiological functions of the homeostatic and pathological processes, including chronic inflammation [5] and tumor biology [6]. More importantly, OPN regulates cell-matrix interactions and cell signaling through binding with integrins and CD44 receptors [3], and thus OPN is widely involved in tumor growth and development.

\section{Structural analysis of Osteopontin}

\section{The SIBLING family}

Small Integrin-Binding Ligand N-linked Glycoprotein family is a group of secreted proteins that are clustered along human chromosome 4, and the secreted proteins include Bone Sialoprotein (BSP), Osteopontin (OPN), Dentin Matrix Protein-1 (DMP1), 
Dentin Sialophosphoprotein (DSPP), and Matrix Extracellular Phosphoglycoprotein (MEPE) [7]. Less homology similarity is found among the five proteins when the primary amino acid sequences are compared singly. The five proteins do, however, share some structural similarities, such as the integrinbinding tripeptide Arg-Gly-Asp (RGD), several post-translational phosphorylation and N-glycosylation sites [8]. Traditionally, the SIBLING families are classified by exon-intron similarities and their biochemical properties in osteogenesis and biomineralization [9]. However, previous research suggested that SIBLING proteins expression is not only observed in mineralized tissues, but it is also observed in different tumor stages which are coupled with Matrix Metalloproteinases (MMPs). For instance, BSP, OPN, and DMP1 of SIBLING are reported to interact with pro-matrix metalloproteinases of MMP-2, MMP-3, and MMP-9, respectively; these indicate a potential role of modulating early tumor behavior [10]. Recently, research has been focused on the roles of OPN in tumorigenesis and metastasis in the past few years compared to other SIBLING family members.

\section{Molecular structure of OPN and tissue distribution}

An alternative translation of single full-length OPN mRNA generates a secreted OPN that regulates the immune response, cell regeneration, and vascularization; an intercellular OPN isoform is also implicated with the cellular process (i.e. migration and motility) [11]. Both the NCBI and UniProt databases (https://www.ncbi.nlm.nih.gov/gene/ 6696 and http://www.uniprot.org/uniprot/P10451 respectively) show five transcript variants encoding different isoforms for SPP1 gene. OPN-a is the full-length isoform chosen as a canonical sequence with the rest of the isoform being compared against OPN-a sequence. While OPN-b lacks exon 5 (missing protein sequence at location 58-71), OPN-c lacks exon 4 (missing protein sequence at location 31-57). Isoform 4 or isoform d lacks two alternate in-frame exons (missing protein sequence at location 95-116) and isoform 5 (missing protein sequence at location 59-72).
OPN gene verifies its chromosome location according to different species, for instance, the genes in mice and pigs are located on chromosome 5 and 8 respectively, and the OPN gene is identified to share approximately $40 \%$ nucleic acid sequence homology with other species, such as mouse, rabbit, cow and pig [1].

OPN is a secreted extracellular glycophosphoprotein [12] and the structure is determined by extensive post-translational modification, such as glycosylation, phosphorylation, sulphation, as well as various cross-linking and proteolytic processes. OPN-a, OPN-b and OPN-c all consist of several highly conserved domains, such as an arginine-glycineaspartic acid (RGD) recognition sequence (GRGDS), SVVYGLR sequence, a thrombin cleavage site (RSK), an aspartic acid rich sequence at its N-terminal, a calcium binding site, and heparin binding domains at its C-terminal [13]. Among the three isoforms, each isoform has a different linking length between the signal peptide and aspartate domain [14] (Figure 1).

OPN is highly expressed in osteoclasts, osteoblasts, vascular and skeletal smooth muscle cells, endothelial cells, lymphocytes, and neural cells (neurons, glial cells, and Schwann cells). It activates immune cells (such as T-cells, B-cells, macrophages, natural killer and Kupffer cells), and it is also secreted by malignant epithelial cells (kidney, breast, and skin) [2, 15-18].

\section{OPN signal mediators}

Integrins are widely expressed in all animal lineages that act as a group of noncovalently-linked heterodimeric transmembrane adhesion receptors through different combinations of $\alpha$ and $\beta$ subunits [19]. The binding receptor family is specifically associated with extracellular matrix, cell surface, or soluble protein ligands, such as vitronectin, fibrinogen, thrombospondin, and OPN [19].

There are two integrin binding domains that have been well identified: RGD domain and a thrombin-cleaved epitope SVVYGLR which is located in the thrombin-cleaved N-terminal fragment of OPN (also named OPN-R or non-RGD domain). The RGD-recognition motif is associated with $a_{v} \beta_{1}, a_{v} \beta_{3}$,

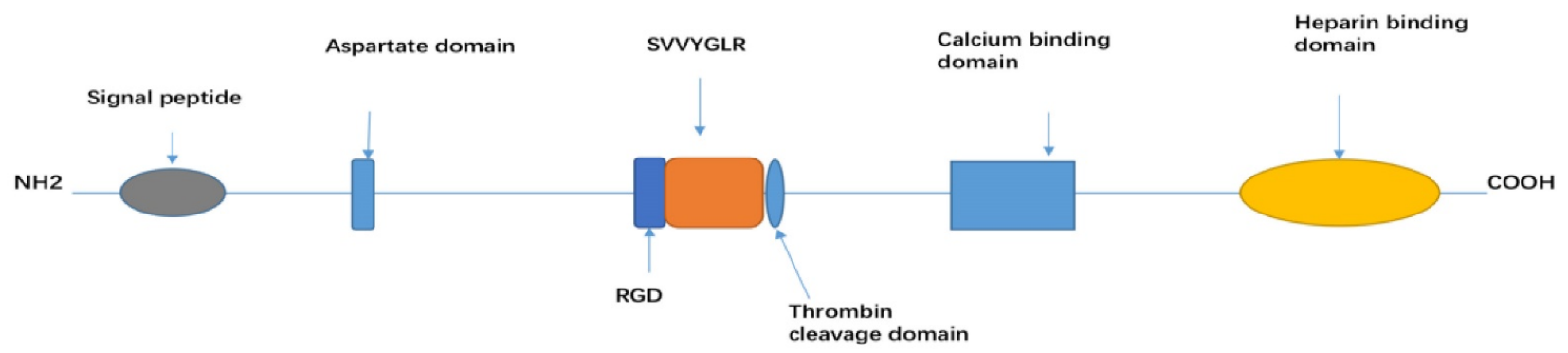

Figure 1. Structure domain of OPN 
$\mathrm{a}_{\mathrm{v}} \beta_{5}, \mathrm{a}_{\mathrm{v}} \beta_{6}, \mathrm{a}_{5} \beta_{1}$, and $\mathrm{a}_{8} \beta_{1}$ integrin isoforms [6], while SVVYGLR domain is interacted with $\alpha_{9} \beta_{1}, \alpha_{9} \beta_{4}, \alpha_{4} \beta_{7}$, and $\alpha_{4} \beta_{1}$ in an RGD-independent manner [20-22]. The interactions between extracellular OPN and cell surface integrin receptors have been identified in some immune cells, such as neutrophils, macrophages, and $\mathrm{T}$ lymphocytes [23, 24]. OPN also participates in activating a series of signal transduction pathways as a result of changes in gene expression levels and various functional expression, including cell adhesion, cell survival, migration, immune regulation, and tumor metastasis [21, 22]. For instance, integrin $\alpha_{v} \beta_{3}$ binding with OPN mediates the signaling pathways of FAK, ERK1/2, and NF- $\mathrm{KB}$ to activate cellular migration [25], and regulates the cellular proliferation and survival via signal transducer and activator of transcription (STAT)-3 signaling pathways $[26,27]$. An OPN-integrin $\alpha_{v} \beta_{3}$ binding also increases the tumor metastasis and decreases the apoptosis via activation of phosphoinositide 3-kinase (PI3K)/Akt/mTOR signaling pathway [22]. Another unique integrin binding site is well-recognized as $\mathrm{N}$-terminal thrombin cleavage fragment of OPN. This cryptic integrin binding site has acted as a chemoattractant for stem and progenitor cells, by mediating cell migration in a manner that involves interaction with $\alpha_{9} \beta_{1}$ and $\alpha_{4} \beta_{1}$ integrins. Unlike other integrin OPN receptors, $\alpha_{9} \beta_{1}$ recognizes only the $\mathrm{N}$-terminal thrombin cleavage fragment of OPN instead of the full-length form [28]. Kale et al. identified that the interaction of OPN with $\alpha_{9} \beta_{1}$ integrin activates ERK and p38 signaling to stimulate COX-2 expression in macrophages [29].

The interaction between OPN and cell surface receptors also occurred in the homing cell adhesion molecule CD44 glycoprotein. CD44 is a cell surface hyaluronan receptor which is ubiquitously expressed in osteoblast, osteoclasts, osteocytes, endothelial cells fibroblasts, epithelial cells, and smooth muscle cells [30]. CD44 plays a role in mediating cell-matrix or cell-cell interactions via various CD44 isoforms that are named as CD44v6-15 [31]. OPN-induced migration of CD44 transfected fibroblasts in Boyden chambers is blocked by CD44, and OPN antibodies indicate a potential interaction between CD44 and OPN. In CD44 positive colorectal cancer cells, the knockdown of CD44 results in a decrease in OPN secretion. The CD44 isoform CD44v6 may be essential for inducing OPN secretion and activating c-jun-NH2kinase signaling pathway, and thus promotes the clonogenicity of colorectal cancer cells [32]. OPN interacts with CD44 via an RGD-independent manner to express different functional activities in chemotaxis of macrophages, cell adhesion of fibroblasts, and cytoprotection and regulation of $\mathrm{T}$ helper type 1 cells and bone marrow cells $[6,30]$.

\section{Biological functions of OPN OPN expression}

The expression of OPN is up-regulated by many factors such as phorbol 12-myristate 13-acetate (PMA), basic fibroblast growth factor (bFGF), parathyroid hormone, retinoic acid, steroids, 1,25-dihydroxy vitamin D3, lipopolysaccharide (LPS), glucocorticosteroids, platelet-derived growth factor, epidermal growth factor (EGF), transforming growth factor-Beta (TGF- $\beta$ ), angiotension II, hyperglycaemia, hypoxia, bone morphogenetic proteins (BMPs), and some inflammatory cytokines such as tumor necrosis factor a (TNFa), interferon gamma (IFN- $\gamma)$ and interleukin-1 $\beta$ (IL-1 $\beta$ ) [33-40]. The expression of OPN is decreased by cGMP-dependent protein kinase regulation in vascular smooth muscle cells [41]. OPN expression also plays a role in the homeostatic regulation, particularly in biomineralization, tissue and bone remodeling, cell-mediated immune response, and wound healing.

\section{Biomineralization and bone remodeling}

As previously mentioned, OPN is widely recognized as a highly expressed non-collagenous protein, mineralized tissues of the bone and teeth, and some ectopic calcification of soft tissues in heart valves, arteries, and kidneys. The various functions of biomineralization are categorized based on the bone mineralized tissue distribution. In the past decades, previous studies have indicated that OPN inhibits mineral deposition, and hydroxyapatite crystal formation and growth. OPN also regulates bone cell adhesion, matrix mineralization, and functions of anchoring osteoclasts to the mineral matrix of bones, as well as its specific affinity for calcium and its immunolocalization in regions of mineralization [4, 37, 42]. Studies have shown that $\mathrm{OPN}^{-/-}$mice have damaged bone resorption which led to the trabecular bone. Additionally, OPN -1 - mice bones are more fragile and hypermineralized than wild type [43, 44].

\section{Cellular immunity and wound healing}

OPN has played a significant role in innate immunity during inflammation and tissue wound healing process. OPN helps to improve the mucosal defense against viral pathogens as a T-helper type-1 (Th1) cytokine. This cytokine regulates inflammatory responses by activating innate immunity of the macrophages, neutrophils, and injured tissues (epithelial cell types and mesenchymal cells) [45, 46]. In OPN null mutant mice, the gene secreted phosphoprotein 1 (SPP1) is upregulated after skin 
incisions. In addition, the mutants showed lower debridement, higher disorganization of the matrix, and alterations of collagen fibrillogenesis [47]. Alternating collage fibrillogenesis would lead to small diameter collagen fibrils in skin wounds. The role of corneal wound healing in OPN-null mice showed that the lack of OPN would result in tissue destruction after an alkali burn [46]. Results suggest that OPN is a good mediator to modulate the fibroblast behavior of wound healing process. Immunohistochemical staining of OPN levels in wound healing in horses and human keloids showed that the expression of OPN was linked to fibroproliferation in horse and human which might have a potential role as a therapeutic approach [48].

\section{The involvement of OPN in tumor biology}

\section{The role of OPN as a biomarker for tumor progression}

Researchers are intensively studying the discovery of disease biomarkers because it has important applications in disease treatment and early diagnosis. Tumor biomarkers are classified into genetic, epigenetic, proteomics, glycomics, and imaging biomarkers. They are substances that can be found in tissue, blood, or other bodily fluids. Tumor biomarkers are usually sensitive and specific to the particular type of tumor, or specific body response related to the presence of cancer $[49,50]$. Tumor markers are widely used as a prime in the diagnosis of early stage cancer and cancer therapy. Examples of these markers are a-fetoprotein in hepatocellular carcinoma [51], neuron-specific enolase (NSE) in the circulation [52, 53], mucinous glycoproteins expressed by human mammary epithelium [54], CA 15-3 in breast cancer [55], and CA-125 in ovarian cancer diagnosis [56, 57].

OPN is commonly found in some mineralized tissues as an extracellular matrix (ECM), and it also behaves as a secreted protein in body fluids, such as milk, blood, urine, saliva, seminal fluid and bile [58]. As a result of its diverse distribution, OPN is involved in multiple steps of tumor biology, including cell proliferation, survival, angiogenesis, chemoresistance, stem-like properties, tumor invasion, and metastasis [59]. Specifically, as referred to the publications through 2000 to 2015 with the keywords 'osteopontin AND cancer' on PubMed database, it is observed that elevated OPN expression in serum samples has been used as a prime mediator of various human cancers. These cancers include but are not limited to malignant breast cancer, osteosarcoma, melanoma, ovarian cancer, endometrial cancer, cervical cancer, renal cancer, oral cancer, esophageal cancer, gastric cancer, colorectal cancer, pancreatic cancer, liver cancer, lung, head and neck cancer, glioblastoma, skin cancer, thyroid cancer, and sarcoma [60, 61]. Table 1 identifies some of the significant pathophysiological OPN roles in selected tissues and their various identification methods. This demonstrated that the up- or downregulation of OPN in these selected tissues has a strong impact on the cancer cell phenotype.

Numerous studies showed that overexpressed OPN in the cancer cells without distinguishing which isomers may consist of functional heterogeneity in a tumor-specific manner [38, 62]. Recent reports have disclosed that OPN isomers in specific cell-type demonstrated different phenotype in malignant tumors [63]. This leads to increase investigation to determine whether multiple isomers are transcriptionally exclusive or inclusively expressed in all cancer cells. As mentioned before, OPN has five isoforms. Related reports indicate that all five isoforms are reported to be co-overexpressed in esophageal adenocarcinoma [64]. While the expression level of OPN isoforms still differs in different tumors or tissues. OPN-a is widely characterized in most types of cancer, OPN-b is more active in lung cancer development, and OPN-c acts as a soluble protein and it is considered as a potential biomarker for breast cancer. OPN-c also participates in lung cancer invasion as confirmed by enhancing cell dissemination [65]. These reports revealed that several OPN isoforms may collectively affect the phenotype, but plausibly with distinctive mechanism routes, such as $\alpha v \beta_{3} / \mathrm{NF \kappa} B / \mathrm{HIF} 1 \alpha$ signaling [64], integrin-dependent and independent signaling, CD44-dependant OPN/Aurora-A/ERK1/2 pathway [64] and PI3K/Akt pathway [62].

The relevant research on the role of OPN in tumorigenicity has been well improved and more systematic. For instance, OPN has been recognized as a unique colon cancer marker by comparing 12,000 human genes and analyzing the correlation of OPN gene expression at advanced Astler Collier (AC) stage [66]. Likui et al. (2011) examined the level of OPN protein expression by the western blot assay using 18 colorectal cancer (CRC) cells and their corresponding normal colon tissue samples [67]. The results indicated that the downregulation of OPN could suppress both in vitro proliferation and in vivo tumorigenicity [67]. Recently, $\mathrm{Ng}$ et al. (2015) investigated OPN plasma levels of 79 patients via ELISA assays, and they correlated the data with the clinicopathological parameters of CRC patients. By comparing plasma OPN level between normal and CRC patients, along with the data supported by in 
vitro model of DLD1 cell migration assay, it is shown that high level of OPN expression activated DLD1 cell migration by overexpressing Snail and Twist1 and repressing E-cadherin [68]. In their further work, the transcription level of OPN in 84 CRC patients was well characterized, and the overexpression of OPN in DLD1-OPN cells induced cell survival and chemoresistance to oxaliplatin treatment. Moreover, OPN overexpression was involved in tumor metastasis and the decrease of the survival rate of CRC patients, by inducing the stem-like property of CRC cells via overexpressing SOX2 [59, 68].

\section{Mechanism of OPN in regulating tumor growth}

Overexpression of OPN has participated in early tumor metastasis and regulated in tumor growth, angiogenesis, and metastasis. The induced high expression of OPN in normal cells is observed to induce neoplastic-like cell behavior including cell invasion in vitro and metastasis in vivo. Transcriptional regulation of OPN is involved in multiple complicated pathways. This includes steroid receptors, AP-1, Sp1, Myc, Oct-1 v-Src, Runx/CBF,
TGF-B/BMPs/Smad/Hox, and Wnt/ Tcf [1, 6, 69]. The participation of various transcription factors such as Ras-response factor (RRF), aryl hydrocarbon receptor (AhR), and Ets transcription factors (Ets-1, Ets-2, ERM, and PEA3) [69] are also included. In some cases, OPN has stimulated the cancer stem cell-mediated tumor progression through inducing high expression of CD44v6 by Wnt- $\beta$-catenin pathway in colorectal cancer patients [70]. Sun et al. reported that the mechanism of the regulatory role of OPN in the hepatocellular carcinoma metastasis might occur through activation of mitogen-activated protein kinase and NF-kB pathways, and MMP-2 [71].

OPN regulates tumor growth, angiogenesis and metastasis, and induces relapses via complicated and multiple signaling pathways. Tumors, as well as stroma-derived OPN, play key roles in various signaling pathways involved in tumor growth, angiogenesis and metastasis. Figure 2 summarizes three important OPN-integrin pathways. One of the pathways is specifically observed in the tumor microenvironment, OPN induces COX-2 and PGE2 secretion through ERK- and p38-dependent AP-1

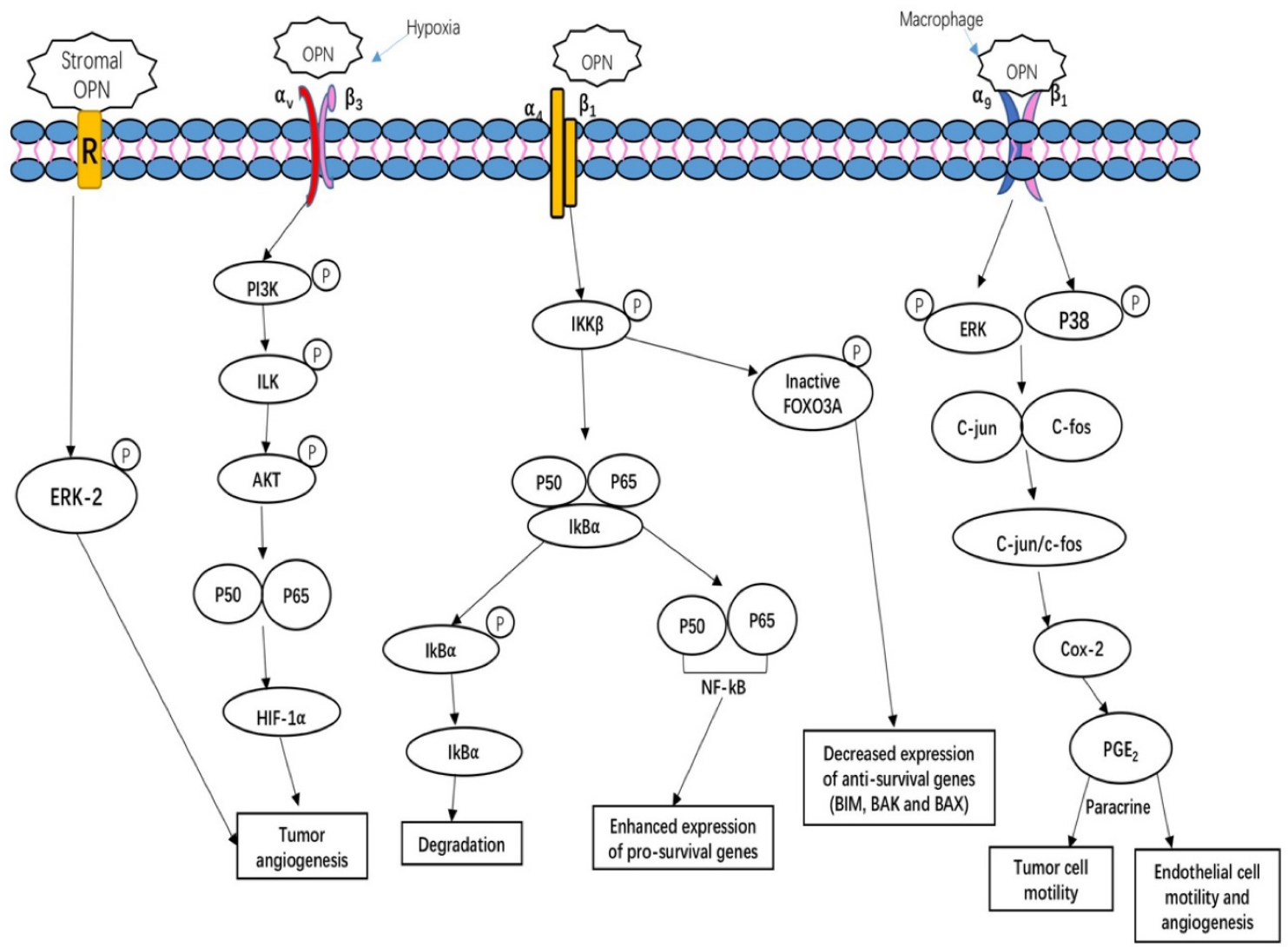

Figure 2. OPN-integrin interaction mediates tumor cell growth and angiogenesis. OPN regulates side population phenotype specifically through ERK2 activation; OPN regulates HIFl $\alpha$-dependent VEGF expression via inducing $\alpha_{v} \beta_{3}$-linked kinase (ILK)/Akt-mediated nuclear factor (NF)-kB p65 activation, thus increasing tumor angiogenesis; OPN induces COX-2 and PGE2 secretion through ERK- and p38-dependent AP-1 activation via $\alpha_{9} \beta_{1}$-integrin, hence enhancing tumor cell motility and angiogenesis; OPN binds to its receptor $\alpha_{4} \beta_{1}$ integrin induces the relapses via the phosphorylation of IKK $\beta$ consequently induces to increase nuclear translocation of $\mathrm{p} 50$ and $\mathrm{p} 65$ subunits of NF-kB. Simultaneously, OPN interaction with $\alpha_{4} \beta_{1}$ integrin also blocks the nuclear translocation of the FOXO3A transcription as a result of blocking the transcription of anti-survival genes such as BIM, BAX and BAK [65, 72, 73, 75]. 
activation via $\alpha_{9} \beta_{1}$-integrin, thus enhancing tumor cell motility and angiogenesis [29]. The other pathway is described by Steinman (2009) that the interaction of OPN $\alpha_{4} \beta_{1}$ integrin stimulates the pro-inflammatory cytokines and inhibiting cell apoptosis. There are three main effects on these key factors. Firstly, OPN binding to $\alpha_{4} \beta_{1}$ integrin activates the phosphorylation of IkB kinase- $\beta$ (IKK- $\beta$ ) thus induces to increase nuclear translocation of p50 and p65 subunits of $\mathrm{NF}-\mathrm{kB}$. The upregulation of NF- $\mathrm{kB}$ can enhance the expression of pro-survival genes and $\mathrm{T}$ helper $1\left(\mathrm{~T}_{\mathrm{H}} 1\right)$ and $\mathrm{T}_{\mathrm{H}} 17$ type cytokines. Meanwhile, OPN induces the degradation of IKBa (inhibitor of NF-KB a-subunit) thus increase the nuclear translocation of NF-kB. Simultaneously, the OPN- $\alpha_{4} \beta_{1}$ interaction also causes the increased phosphorylation of the transcription factor forkhead box O3A (FOXO3A) which exclude the nuclear translocation of FOXO3A, thus decreases the anti-survival genes expression, such as BCL-2-interacting mediator of cell death (BIM), BCL-2-associated X protein (BAX) and BCL-2 antagonist/killer (BAK) [72]. Moreover, hypoxia is a unique parameter in tumor angiogenesis, malignancy, invasion and metastasis. The key regulator of hypoxia phenomena is hypoxia-inducible factor 1-a (HIF1a). Under hypoxia condition, OPN regulates HIF1adependent VEGF expression via inducing $\alpha_{v} \beta_{3}$-linked kinase (ILK)/Akt-mediated nuclear factor (NF)-KB p65 activation [73]. Kumar et al. have shown that stroma-derived OPN regulates side population phenotype specifically through ERK2 activation thus playing a crucial role in modulating melanoma growth and angiogenesis [74] (Figure 2).

\section{The conjunction roles of OPN with other biomarkers in cancer development}

Cancer development is a complex process that involves combinations roles of various tumor and tumor stroma-derived growth factors and cytokines. There has been an increasing recognition that the combination role of different biomarkers would improve the prognostic sensitivity than the individual marker. OPN has been investigated in various tumor tissues or in blood samples to analyze its conjunction role with other markers. In 2011, Weber reviewed that the clinical role of OPN was related to the tumor stage, tumor grade and early tumor progression.

Table 1. The presence and significance of OPN in different cancer cells and their detection methods.

\begin{tabular}{|c|c|c|c|}
\hline Human tissue & Pathophysiology behavior & Detection Method(s) & Reference \\
\hline Colon & $\begin{array}{l}\text { The downregulation of OPN could suppress } \\
\text { both in vitro proliferation and in vivo } \\
\text { tumorigenicity of colon cancer. }\end{array}$ & $\begin{array}{l}\text { Western blot analysis was performed on a series of OPN protein expression in } 18 \\
\text { colorectal cancer (CRC) cells and the corresponding normal colon tissue samples. }\end{array}$ & [67] \\
\hline Breast & $\begin{array}{l}\text { OPN is highly expressed and secreted by } \\
\text { breast tumor cells; it activates fibroblasts with } \\
\text { a promoting growth-permissive desmoplastic } \\
\text { stroma. }\end{array}$ & $\begin{array}{l}\text { High-throughput LC/MS-MS method to analyze breast cancer cell-secreted } \\
\text { factors, including immunohistochemistry/immunofluorescence of } \\
\text { paraffin-embedded tissue, and orthotopic tumors model construction. }\end{array}$ & [76] \\
\hline $\begin{array}{l}\text { Pancreatic } \\
\text { Adenocarcinoma }\end{array}$ & $\begin{array}{l}\text { Strong OPN mRNA signal in } \\
\text { tumor-infiltrating macrophages was } \\
\text { observed in } 8 \text { of } 14 \text { pancreatic } \\
\text { adenocarcinomas. Serum OPN levels were } \\
\text { elevated, and this suggested serum OPN } \\
\text { might be a potential biomarker for pancreatic } \\
\text { cancer. }\end{array}$ & $\begin{array}{l}\text { Pancreatic adenocarcinoma tissue microarray was analyzed via in situ } \\
\text { hybridization method; competitive ELISA was performed to test serum levels in } \\
\text { preoperative sera of } 50 \text { patients and } 22 \text { healthy control individuals. }\end{array}$ & [77] \\
\hline Prostate & $\begin{array}{l}\text { OPN signal was overexpressed } \\
\text { in prostate cancer (PCa) and OPN splicing } \\
\text { isoform (OPN-SI). This suggested OPN could } \\
\text { be an important biomarker forPCa diagnosis } \\
\text { and prognosis. }\end{array}$ & $\begin{array}{l}\text { Quantitative real time PCR was used to measure OPN-SI mRNA expression; } \\
\text { anti-OPNc polyclonal antibody was tested by immunohistochemical staining; } \\
\text { OPN-SI and total prostate specific antigen (PSA) serum levels of clinical and } \\
\text { pathological data were investigated. }\end{array}$ & [78] \\
\hline $\begin{array}{l}\text { Oral squamous cell } \\
\text { carcinoma (OSCC) }\end{array}$ & $\begin{array}{l}\text { Overexpression of OPN in OSCC cells led to } \\
5 \text {-FU resistance and abrogated the } \\
\text { prosurvival effect of the drug in the mouse } \\
\text { xenograft model. }\end{array}$ & $\begin{array}{l}\text { Gene expression microarray analysis was performed on the biopsy specimens of } \\
\text { six patients with OSCC, and qRT-PCR was performed on the } 49 \text { OSCC patient } \\
\text { samples. }\end{array}$ & [79] \\
\hline Gastric & $\begin{array}{l}\text { OPN activates the gastric cancer behavior } \\
\text { through the NF-kB pathway which is } \\
\text { regulated by the MAPK and PI3K. }\end{array}$ & $\begin{array}{l}\text { In vivo and in vitro experimental methods were employed to investigate tumor } \\
\text { growth that includes growth curves, apoptosis assay, invasion assay and } \\
\text { migration assay. Moreover, mouse xenograft models of human gastric cancer } \\
\text { were used. }\end{array}$ & {$[80]$} \\
\hline Lung & $\begin{array}{l}\text { The level of OPN expression in lung } \\
\text { adenocarcinomas was associated with tumor } \\
\text { cell survival and } a_{v} \text { integrin expression. }\end{array}$ & $\begin{array}{l}\text { The tissue microarray was constructed, and tissues were analyzed by } \\
\text { immunohistochemistry to determinate OPN and } a_{\mathrm{v}} \text { integrin expression. TUNEL } \\
\text { method was used to detect DNA strand break generated during cell apoptosis. }\end{array}$ & {$[24]$} \\
\hline Ovarian & $\begin{array}{l}\text { Regulation of OPN is involved in carcinoma } \\
\text { cell invasion. }\end{array}$ & $\begin{array}{l}\text { Immunofluorescence analysis was performed to detect OPN in a total of } 160 \\
\text { patient-derived specimens. }\end{array}$ & [81] \\
\hline Liver & $\begin{array}{l}\text { The OPN levels were likely correlated with } \\
\text { the degree of liver necrosis in acute liver } \\
\text { failure (ALF). Higher expression was } \\
\text { observed in hyperacute injury. }\end{array}$ & $\begin{array}{l}\text { Quantikine }{ }^{\circledR} \text { ELISA assay was carried out on OPN plasma from an experimental } \\
\text { group of } 105 \text { consecutive ALF patients, a control group of } 40 \text { patients with } \\
\text { rheumatoid arthritis and } 35 \text { healthy subjects. An acute inflammation model } \\
\text { construction with duration of } 1 \text { and } 3 \text { days was investigated after undergoing } \\
\text { spine fusion surgery. }\end{array}$ & {$[82]$} \\
\hline
\end{tabular}


Researchers performed a meta-analysis on the OPN's conjunction role with cancer-specific markers, such as functionally converging biomolecules (bone, angiogenesis, motility/adhesion, extracellular matrix) and synergizing biomolecules (fibrinolytic system, calcium homeostatic proteins, squamous cell carcinoma antigen, NF-KB pathways, proteases) [61]. Since then, research started to focus on the conjunction role of OPN with other specific tumor markers. Sun et al. reported that the combination of OPN and CD44v6 would improve the sensitivity and predictive range for the patients with Stage I non-small cell lung cancer [83]. In 2014, Zhu et al. performed tissue microarraybased immunohistochemistry to investigate OPN and peritumor-infiltrating macrophages (PTMs) expression in two independent cohorts consisting of 96 and 278 early-stage hepatocellular carcinomas (HCC) patients respectively. Results indicate that the combination of OPN and PTM levels may have a better prognostic value for HCC in early stage patients [84]. In 2015, Ramchandani and Weber demonstrated that OPN and VEGF may act as co-expressing or co-inducing molecules in response to hypoxia and cell apoptosis [85]. In some cases, the knockdown of OPN expression will affect the VEGF although they work through distinct pathways [85]. In the same year, the co-existence role of OPN and M2 tumor-associated macrophages (M2-TAMs) in gastric cancer was demonstrated by Lin and colleagues [86]. They carried out immunohistochemical staining in 170 resected gastric cancer specimens that were collected from 1998 to 2012 and determined the correlation of OPN and M2-TAMs expression respectively. The results show that the co-existence of OPN and M2-TAMs is involved in disease progression and poor survival and would provide better conjunction prognostic marker in clinical practice [86]. Moreover, $\mathrm{Zhu}$ et al. reviewed a meta-analysis that determines the diagnostic values of OPN combined with CA125 for ovarian cancer. The results show that the combination of OPN with CA125 increases the sensitivity and specificity respectively [87]. The research data would be a good approach to understand the significant role of OPN combined with other tumor markers, and their clinical correlation needs further investigation.

\section{Therapeutic approaches on OPN inhibitor}

As mentioned above, OPN, a chemokine-like protein, is involved in enhancing necrosis of tumor by regulating various aspects of tumor progression such as cell proliferation, survival, drug resistance, invasion, stem-like behavior, angiogenesis and metastasis [67, 69]. Current research indicates that
OPN inhibition would be a good therapeutic approach to metastatic disease. Wu et al. demonstrated that $\mathrm{OPN}^{-/-}$mice have slower tumor growth after Ras transformation, and similarly the $\mathrm{OPN}^{-/-}$ B16 melanoma cells have showed reduced metastases to soft tissues and bone [88, 89]. Bandopadhyay et al. reviewed that the application of RNAi such as small interfering RNA (siRNA) and short hairpin RNAs (shRNAs) against OPN as a potential therapeutic strategy [75]. Moreover, employment of aptamers, antibodies, and small molecular inhibitors would inhibit OPN expression. Wu and researchers (2014) carried out an OPN knockdown experiment of colon cancer cells using four siRNA of target OPN gene that were inserted into a pGPU6/GFP/Neo expression vector and subsequently transfected into human colon cancer cell line (LoVo). The results showed that silencing of OPN mediated by siRNA also inhibited the expression of VEGF, MMP-2, MMP-9 and urokinase plasminogen activator in LoVo cells. These effects might decrease invasion and angiogenesis of colon cancer [90]. Similarly, the downregulation of OPN via recombinant plasmid expressing siRNA also reduces the HIF-1 and VEGF proteins in MDA-MB-343 cells and decreases cell invasion, increases cell apoptosis and cell senescence [91]. Blocking antibodies to OPN and its specific receptors CD44 and $\alpha_{v} \beta_{3}$-integrin also showed inhibitory role of different cancer and stromal cell migration. For instance, Mi et al. showed that the blocking antibody targeting the CD44 on mesenchymal stromal cells (MSCs) reduced the OPN-induced tumor growth of the chemokine CCL5 in MSCs [92]. The disrupting OPN binding to 4T1 cell-surface integrins by the competitive ligand inhibitor, RGD, or a blocking antibody to $\alpha_{v} \beta_{3}$-integrin decreases the expression of ILK, uroplasminogen activator (uPA) and MMP-2 in murine mammary epithelial cancer cells [93]. Some small molecular inhibitors that influence tumor behavior through targeting OPN has gained crucial acceptance. Kumar et al. have reported that Andrographolide (Andro), a natural diterpenoid lactone isolated from Andrographis paniculata has been shown to inhibit OPN expression and breast cancer cell proliferation, migration through downregulation of PI3kinase/Akt signaling pathway [94]. Furthermore, aptamers, short single-stranded RNA (ssRNA) oligonucleotides (12-30nt) are considered as a good therapy due its high stability, resistance to immunogenicity and high efficacy in low dose [75]. OPN-R3 aptamer was used to inactivate the extracellular OPN and disturb surface binding of OPN to its cell surface CD44 and $\alpha_{v} \beta_{3}$ integrin receptors, and decreased the level PI3K, JNK1/2, Src and Akt, and mediators of extracellular matrix 
degradation, matrix MMP-2 and uPA in MDA-MB231 human breast cancer cells [95].

Moreover, microRNAs (miRNAs) are classes of non-coding RNA molecules that participate in cell differentiation, proliferation, survival and metastasis by binding to complementary target mRNAs, resulting in mRNA translational inhibition or degradation [96]. miRNAs have been used as a diagnostic and prognostic biomarker for defining the origin of tumors in poorly differentiated cancers due to its tissue specificity. For example, hsa-miR-299-5p has been reported to target OPN in three human breast cancer cell lines (MCF7, MCF10AT and MCF10DCIS.com) and regulate the expression of OPN [97]. miRNA 181a targets OPN and decreases OPN expression in hepatocellular cancer cell lines (Hep 3B and Hep G2) [98]. The mature miRNA is processed into a dsRNA that resembles a siRNA, except that base pairing is imperfect and the duplex typically contains small bulges. Nowadays, new siRNA-based therapeutics have been proposed to inhibit or enhance the endogenous miRNA pathway according to the chemical similarity of miRNA and siRNA [99]. RNA interference (RNAi) is a posttranscriptional gene silencing strategy that is specific for the evolutionarily conserved sequence, and lentiviralbased expression systems could mediate a longlasting RNAi-based gene knockdown [71]. Sun et al. demonstrated that lentiviral RNAi expression vectors with specific miRNA against OPN suppress tumor growth and metastasis of human hepatocellular carcinoma [71].

\section{Conclusion}

Currently, researchers are studying the discovery of cancer biomarkers as their potential specificity and sensitivity to the particular type of tumor. OPN is involved in tumor biology in multiple ways, such as multi-transcription factors, gene coexpression, and co-regulation steps. In the past few years, intensive research has been done to determine whether OPN is a useful diagnostic and therapeutic biomarker for different types of cancer. The various isoforms of OPN demonstrate different phenotype in malignant tumors. This leads to increased investigation to determine whether multiple isomers are transcriptionally exclusive or inclusively expressed in all cancer cells. The highly conserved structural domains of OPN have determined its various biological activities that involve in promoting CD44 and integrin-mediated tumor migration, invasion and angiogenesis. Meanwhile, the possibilities of the conjunction roles of OPN with other biomarkers to improve the prognostic sensitivity also need further attention. Clinical databases indicate that the OPN is associated with patients' survival rate from different patient samples. The therapeutic approaches of OPN knockdown using RNAi, such as siRNA, shRNAs, aptamers, antibodies, and small molecular, as well as the miRNA-based therapeutics have shown to have active roles in cancer treatment. Although there are a considerable number of therapeutic approaches based on preclinical studies, only a small number of the findings translate into clinical practice. For instance for the miRNA-based therapy previously mentioned, there are still a few issues that need to be resolved prior to clinical trial. First, many factors such as hypoxia and inflammation in tumor microenvironment result in significant heterogeneity of miRNA expression, and this creates many obstacles in identifying the target miRNA to specific disease type. Another big challenge is how to design miRNA delivery vehicles that have high in vivo stability and sensitive tissue recognition and lower toxicity. All these issues also need to be addressed in other OPN-based therapeutic research. In clinical research, sometimes solely knockdown of specific target gene might cause some side effect or even tumor aggressive. A systematic comparison between these therapeutic methods is worth further investigation. Blocking or silencing of OPN might also result in other severe adverse effect due to the interference with normal OPN regulation roles [100]. Investigation into the interaction of OPN with other regulatory genes in tumor/cancer treatment will help solve this problem. Although the data of the structural and cellular mechanisms in determining the therapeutic roles of OPN are still incomplete, future research is needed to elucidate the roles of OPN in different human diseases. For example, Tu et al demonstrated that miRNA-127-5p is an important regulator of OPN in human chondrocytes and may contribute to the development of osteoarthritis research [101]. In theory, exploring the underlying molecular mechanism of OPN will facilitate the development of novel therapeutic strategies to improve cancer treatment, and broaden our view towards other diseases.

\section{Abbreviations}

OPN: osteopontin; SPP1: a secreted phosphorprotein 1; ETA1: Early T-lymphocyte Activation 1; SIBLING: Small Integrin-Binding Ligand N-linked Glycoprotein family; BSP: Bone Sialoprotein; DMP1: Dentin Matrix Protein-1; DSPP: Dentin Sialophosphoprotein; MEPE: Matrix Extracellular Phosphoglycoprotein; MMPs: Matrix Metalloproteinases; PMA: phorbol 12-myristate 13-acetate; LPS: lipopolysaccharide; EGF: epidermal growth factor; TGF- $\beta$ : transforming growth factor-Beta; BMPs: bone 
morphogenetic proteins; $\mathrm{TNF} a$ : tumor necrosis factor $a$; IFN- $\gamma$ : interferon gamma; IL-1 $\beta$ : interleukin- $1 \beta$; Th1: T-helper type-1; NSE: Neuron-specific enolase; ECM: extracellular matrix; AC: Astler Collier; CRC: colorectal cancer; VPF/VEGF: vascular permeability factor/vascular endothelial growth factor; HIF1adependent: hypoxia-inducible factor-1a-dependent; ALF: acute liver failure; RA: rheumatoid arthritis; PSA: Prostate Specific Antigen; SF: spine fusion; OPN-SI: OPN splicing isoform; PTMs: peritumorinfiltrating macrophages; M2-TAMs: M2 tumor -associated macrophages; siRNA: small interfering RNA; shRNAs: short hairpin RNAs; MSCs: mesenchymal stromal cells; uPA: uroplasminogen activator; Andro: Andrographolide; ssRNA: single-stranded RNA; IKK- $\beta$ : IkB kinase- $\beta$; FOXO3A: forkhead box O3A; BIM: BCL-2-interacting mediator of cell death; BAX: BCL-2-associated $X$ protein; BAK: BCL-2 antagonist/killer.

\section{Acknowledgments}

This review article was supported by the University of Macau Multi-Year Research Grant (MYRG2015-00065-FHS) to Prof Hang Fai Kwok's research group.

\section{Competing Interests} interests.

The authors declare that they have no competing

\section{References}

1. El-Tanani MK, Campbell FC, Kurisetty V, Jin D, McCann M, Rudland PS: The regulation and role of osteopontin in malignant transformation and cancer. Cytokine Growth Factor Rev 2006, 17(6):463-474.

2. Senger DR, Wirth DF, Hynes RO: Transformed mammalian cells secrete specific proteins and phosphoproteins. Cell 1979, 16(4):885-893.

3. Pagel CN, Wijesinghe DKW, Esfandouni NT, Mackie EJ: Osteopontin, inflammation and myogenesis: influencing regeneration, fibrosis and size of skeletal muscle. J cell Commun Signal 2014, 8(2):95-103.

4. Giachelli CM, Steitz S: Osteopontin: a versatile regulator of inflammation and biomineralization. Matrix Biol 2000, 19(7):615-622.

5. Lund SA, Giachelli CM, Scatena M: The role of osteopontin in inflammatory processes. J cell Commun Signal 2009, 3(3-4):311-322.

6. Wai PY, Kuo PC: Osteopontin: regulation in tumor metastasis. Cancer Metastasis Rev 2008, 27(1):103-118.

7. Fisher L, Torchia D, Fohr B, Young M, Fedarko N: Flexible structures of SIBLING proteins, bone sialoprotein, and osteopontin. Biochem Biophys Res Commun 2001, 280(2):460-465.

8. Fedarko NS, Jain A, Karadag A, Van Eman MR, Fisher LW: Elevated serum bone sialoprotein and osteopontin in colon, breast, prostate, and lung cancer. Clin Cancer Res 2001, 7(12):4060-4066.

9. Yang X, Yan W, Tian Y, Ma P, Opperman LA, Wang X: Family with sequence similarity member $20 \mathrm{C}$ is the primary but not the only kinase for the small-integrin-binding ligand N-linked glycoproteins in bone. FASEB J 2015, 30(1):121-128

10. Fisher LW, Jain A, Tayback M, Fedarko NS: Small integrin binding ligand $\mathrm{N}$-linked glycoprotein gene family expression in different cancers. Clin Cancer Res 2004, 10(24):8501-8511.

11. Shinohara ML, Kim HJ, Kim JH, Garcia VA, Cantor H: Alternative translation of osteopontin generates intracellular and secreted isoforms that mediate distinct biological activities in dendritic cells. Proc Natl Acad Sci 2008, 105(20):7235-7239.

12. El-Tanani MK: Role of osteopontin in cellular signaling and metastatic phenotype. Front Biosci 2008, 13:4276-4284.

13. Denhardt DT, Guo X: Osteopontin: a protein with diverse functions. FASEB J 1993, 7(15):1475-1482.
14. Cao D, Li Z, Jiang X, Lum YL, Khin E, Lee NP, Wu G, Luk JM: Osteopontin as potential biomarker and therapeutic target in gastric and liver cancers. World J Gastroenterol 2012, 18(30):3923.

15. O'Brien ER, Garvin MR, Stewart DK, Hinohara T, Simpson JB, Schwartz SM, Giachelli CM: Osteopontin is synthesized by macrophage, smooth muscle, and endothelial cells in primary and restenotic human coronary atherosclerotic plaques. Arterioscler Thromb 1994, 14(10):1648-1656.

16. Malyankar UM, Almeida M, Johnson RJ, Pichler RH, Giachelli CM: Osteopontin regulation in cultured rat renal epithelial cells. Kidney Int 1997, 51(6):1766-1773.

17. Craig AM, Denhardt DT: The murine gene encoding secreted phosphoprotein 1 (osteopontin): promoter structure, activity, and induction in vivo by estrogen and progesterone. Gene 1991, 100:163-171.

18. Syn WK, Choi SS, Liaskou $\mathrm{E}$, Karaca GF, Agboola KM, Oo YH, Mi Z, Pereira TA, Zdanowicz M, Malladi P, Chen Y, Moylan C, Jung Y, Bhattacharya SD, Teaberry V, Omenetti A, Abdelmalek MF, Guy CD, Adams DH, Kuo PC, Michelotti GA, Whitington PF, Diehl AM: Osteopontin is induced by hedgehog pathway activation and promotes fibrosis progression in nonalcoholic steatohepatitis. Hepatology 2011, 53(1):106-115.

19. Iwamoto DV, Calderwood DA: Regulation of integrin-mediated adhesions. Curr Opin Cell Biol 2015, 36:41-47.

20. Denhardt DT, Noda M, O'Regan AW, Pavlin D, Berman JS: Osteopontin as a means to cope with environmental insults: regulation of inflammation, tissue remodeling, and cell survival. J Clin Invest 2001, 107(9):1055-1061.

21. Chen Q, Shou P, Zhang L, Xu C, Zheng C, Han Y, Li W, Huang Y, Zhang X, Shao C: An Osteopontin-Integrin Interaction Plays a Critical Role in Directing Adipogenesis and Osteogenesis by Mesenchymal Stem Cells. Stem Cells 2014, 32(2):327-337.

22. Zhang H, Guo M, Chen JH, Wang Z, Du XF, Liu PX, Li WH: Osteopontin knockdown inhibits alphav, beta3 integrin-induced cell migration and invasion and promotes apoptosis of breast cancer cells by inducing autophagy and inactivating the PI3K/Akt/mTOR pathway. Cell Physiol Biochem 2014, 33(4):991-1002.

23. Dalal S, Zha Q, Daniels CR, Steagall RJ, Joyner WL, Gadeau AP, Singh M, Singh K: Osteopontin stimulates apoptosis in adult cardiac myocytes via the involvement of CD44 receptors, mitochondrial death pathway, and endoplasmic reticulum stress. Am J Physiol Heart Circ Physiol 2014, 306(8):H1182-91.

24. Stemberger C, Matusan-Ilijas K, Avirovic M, Bulat-Kardum L, Ivancic A, Jonjic $\mathrm{N}$, Lucin K: Osteopontin is associated with decreased apoptosis and alphav integrin expression in lung adenocarcinoma. Acta Histochem 2014, 116(1):222-229.

25. Zou C, Luo Q, Qin J, Shi Y, Yang L, Ju B, Song G: Osteopontin promotes mesenchymal stem cell migration and lessens cell stiffness via integrin beta1, FAK, and ERK pathways. Cell Biochem Biophys 2013, 65(3):455-462.

26. Behera R, Kumar V, Lohite K, Karnik S, Kundu GC: Activation of JAK2/STAT3 signaling by osteopontin promotes tumor growth in human breast cancer cells. Carcinogenesis 2010, 31(2):192-200.

27. Hui T, Sørensen ES, Rittling SR: Osteopontin binding to the alpha 4 integrin requires highest affinity integrin conformation, but is independent of post-translational modifications of osteopontin. Matrix Biol 2015, 41:19-25.

28. Grassinger J, Haylock DN, Storan MJ, Haines GO, Williams B, Whitty GA Vinson AR, Be CL, Li S, Sorensen ES, Tam PP, Denhardt DT, Sheppard D, Choong PF, Nilsson SK: Thrombin-cleaved osteopontin regulates hemopoietic stem and progenitor cell functions through interactions with alpha9beta1 and alpha4beta1 integrins. Blood 2009, 114(1):49-59.

29. Kale S, Raja R, Thorat D, Soundararajan G, Patil T, Kundu G: Osteopontin signaling upregulates cyclooxygenase-2 expression in tumor-associated macrophages leading to enhanced angiogenesis and melanoma growth via a9ß1 integrin. Oncogene 2014, 33(18):2295-2306.

30. Denhardt DT, Guo X: Osteopontin: a protein with diverse functions. FASEB J 1993, 7(15):1475-1482.

31. Trapasso S, Garozzo A, Belfiore A, Allegra E: Evaluation of the CD44 isoform v-6 (sCD44var, v6) in the saliva of patients with laryngeal carcinoma and its prognostic role. Cancer Biomark 2016, 16(2):275-280.

32. Rao G, Wang $H$, Li B, Huang L, Xue D, Wang X, Jin H, Wang J, Zhu Y, Lu Y, Du L, Chen Q: Reciprocal interactions between tumor-associated macrophages and CD44-positive cancer cells via osteopontin/CD44 promote tumorigenicity in colorectal cancer. Clin Cancer Res 2013, 19(4):785-797.

33. Zhang GX, Zhao ZQ, Wang HD, Hao B: Enhancement of osteopontin expression in HepG2 cells by epidermal growth factor via phosphatidylinositol 3-kinase signaling pathway. World J Gastroenterol 2004, 10(2):205-208.

34. Gauer S, Hauser IA, Obermuller N, Holzmann Y, Geiger H, Goppelt-Struebe M: Synergistic induction of osteopontin by aldosterone and inflammatory cytokines in mesangial cells. J Cell Biochem 2008, 103(2):615-623.

35. Noda M, Yoon K, Prince CW, Butler WT, Rodan GA: Transcriptional regulation of osteopontin production in rat osteosarcoma cells by type beta transforming growth factor. J Biol Chem 1988, 263(27):13916-13921.

36. Noda M, Rodan GA: Transcriptional regulation of osteopontin production in rat osteoblast-like cells by parathyroid hormone. J Cell Biol 1989, 108(2):713-718

37. Gericke A, Qin C, Spevak L, Fujimoto Y, Butler WT, Sørensen ES, Boskey AL: Importance of Phosphorylation for Osteopontin Regulation of Biomineralization. Calcif Tissue Int 2005, 77(1):45-54 
38. Sodek J, Ganss B, McKee MD: Osteopontin. Crit Rev Oral Biol Med 2000, 11(3):279-303

39. Mazzali M, Kipari T, Ophascharoensuk V, Wesson JA, Johnson R, Hughes J: Osteopontin - a molecule for all seasons. QJM 2002, 95(1):3.

40. Li X, O'Regan AW, Berman JS: IFN-ץ induction of osteopontin expression in human monocytoid cells. J Interferon Cytokine Res 2003, 23(5):259-265.

41. Dey NB, Boerth NJ, Murphy-Ullrich JE, Chang PL, Prince CW, Lincoln TM: Cyclic GMP-dependent protein kinase inhibits osteopontin and thrombospondin production in rat aortic smooth muscle cells. Circ Res 1998, 82(2):139-146.

42. Steitz SA, Speer MY, McKee MD, Liaw L, Almeida M, Yang H, Giachelli CM: Osteopontin inhibits mineral deposition and promotes regression of ectopic calcification. Am J Pathol 2002, 161(6):2035-2046.

43. Scatena M, Liaw L, Giachelli CM: Osteopontin: a multifunctional molecule regulating chronic inflammation and vascular disease. Arterioscler Thromb Vasc Biol 2007, 27(11):2302-2309.

44. Kitahara K, Ishijima M, Rittling SR, Tsuji K, Kurosawa H, Nifuji A, Denhardt DT, Noda M: Osteopontin deficiency induces parathyroid hormone enhancement of cortical bone formation. Endocrinology 2003, 144(5):2132-2140.

45. Wang KX, Denhardt DT: Osteopontin: role in immune regulation and stress responses. Cytokine Growth Factor Rev 2008, 19(5):333-345.

46. Miyazaki K, Okada Y, Yamanaka O, Kitano A, Ikeda K, Kon S, Uede T, Rittling SR, Denhardt DT, Kao WW, Saika S: Corneal wound healing in an osteopontin-deficient mouse. Invest Ophthalmol Vis Sci 2008, 49(4):1367-1375.

47. Liaw L, Birk DE, Ballas CB, Whitsitt JS, Davidson JM, Hogan BL: Altered wound healing in mice lacking a functional osteopontin gene (spp1). J Clin Invest 1998, 101(7):1468-1478.

48. Miragliotta V, Pirone A, Donadio E, Abramo F, Ricciardi MP, Theoret CL: Osteopontin expression in healing wounds of horses and in human keloids. Equine Vet J 2016, 48(1):72-77.

49. Chatterjee SK, Zetter BR: Cancer biomarkers: knowing the present and predicting the future. Future Oncology 2005, 1(1): 37-50

50. Mishra A, Verma M: Cancer biomarkers: are we ready for the prime time? Cancers 2010, 2(1):190-208.

51. Oka H, Tamori A, Kuroki T, Kobayashi K, Yamamoto S: Prospective study of a-fetoprotein in cirrhotic patients monitored for development of hepatocellular carcinoma. Hepatology 1994, 19(1):61-66.

52. Lindblom A, Liljegren A: Regular review: tumour markers in malignancies. BMJ 2000, 320(7232):424-427.

53. Lamberts SWJ, Hofland LJ, Nobels FRE, Lamberts SWJ, Hofland LJ, Nobels FRE: Neuroendocrine Tumor Markers. Front Neuroendocrinol 2001, 22(4):309-339.

54. Gendler SJ, Burchell JM, Duhig T, Lamport D, White R, Parker M, Taylor-Papadimitriou J: Cloning of partial cDNA encoding differentiation and tumor-associated mucin glycoproteins expressed by human mammary epithelium. Proc Natl Acad Sci 1987, 84(17):6060-6064

55. Safi F, Kohler I, Beger H, Röttinger E: The value of the tumor marker CA 15-3 in diagnosing and monitoring breast cancer. A comparative study with carcinoembryonic antigen. Cancer 1991, 68(3):574-582

56. Jacobs I, Oram D, Fairbanks J, Turner J, Frost C, Grudzinskas J: A risk of malignancy index incorporating CA 125, ultrasound and menopausal status for the accurate preoperative diagnosis of ovarian cancer. BJOG: An International Journal of Obstetrics \& Gynaecology 1990, 97(10):922-929.

57. Hu Z, Wei T, Yang M, Ma N, Tang O, Oin B, Fu H, Zhong R: Diagnostic Value of Osteopontin in Ovarian Cancer: A Meta-Analysis and Systematic Review. PLoS ONE 2015, 10(5):e0126444.

58. Subraman V, Thiyagarajan $M$, Malathi N, Rajan ST: OPN-Revisited. JCDR 2015, 9(6):10.

59. Ng L, Wan T, Chow A, Iyer D, Man J, Chen G, Yau TC, Lo O, Foo C, Poon JT, Poon RT, Pang R, Law W: Osteopontin Overexpression Induced Tumor Progression and Chemoresistance to Oxaliplatin through Induction of Stem-Like Properties in Human Colorectal Cancer. Stem Cells Int 2015, 2015:1-8.

60. Weber GF, Lett GS, Haubein NC: Osteopontin is a marker for cancer aggressiveness and patient survival. Br J Cancer 2010, 103(6):861.

61. Weber GF: The cancer biomarker osteopontin: combination with other markers. Cancer Genomics Proteomics 2011, 8(6):263-288

62. Tilli TM, Franco VF, Robbs BK, Wanderley JL, da Silva FR, de Mello KD, Viola JP, Weber GF, Gimba ER: Osteopontin-c splicing isoform contributes to ovarian cancer progression. Mol Cancer Res 2011, 9(3):280-293.

63. Phillips RJ, Helbig KJ, Van der Hoek, Kylie H, Seth D, Beard MR: Osteopontin increases hepatocellular carcinoma cell growth in a CD44 dependant manner. World J Gastroenterol 2012, 18(26):3389-3399.

64. Lin I, Myers AL, Wang Z, Nancarrow DJ, Ferrer-Torres D, Handlogten A Leverenz K, Bao J, Thomas DG, Wang TD, Orringer MB, Reddy RM, Chang AC, Beer DG, Lin L: Osteopontin (OPN/SPP1) isoforms collectively enhance tumor cell invasion and dissemination in esophageal adenocarcinoma. Oncotarget 2015, 6(26):22239-22257.

65. Butti R, Ghosh P, Totakura KV, Venkata RNN, Nimma R, Kundu GC: Role of Osteopontin in Tumor Microenvironment: A New Paradigm in Cancer Therapy. In Multi-Targeted Approach to Treatment of Cancer. Edited by Anonymous Springer; 2015:113-125.

66. Wai PY, Kuo PC: Osteopontin: regulation in tumor metastasis. Cancer Metastasis Rev 2008, 27(1):103-118.
67. Likui $W$, Hong $W$, Shuwen $Z$, Yuangang $Y$, Yan $W$ : The potential of osteopontin as a therapeutic target for human colorectal cancer. J Gastrointest Surg 2011, 15(4):652-659.

68. Ng L, Wan TM, Lam CS, Chow AK, Wong SK, Man JH, Li H, Cheng NS, Pak RC, Cheung AH, Yau TC, Lo OS, Foo DC, Poon JT, Poon RT, Pang RW, Law W: Post-Operative Plasma Osteopontin Predicts Distant Metastasis in Human Colorectal Cancer. PLoS ONE 2015, 10(5):e0126219.

69. Shevde LA, Samant RS: Mini review: Role of osteopontin in the pathophysiology of cancer. Matrix Biol 2014, 37:131-141.

70. Todaro M, Gaggianesi M, Catalano V, Benfante A, Iovino F, Biffoni M, Apuzzo T, Sperduti I, Volpe S, Cocorullo G: CD44v6 is a marker of constitutive and reprogrammed cancer stem cells driving colon cancer metastasis. Cell Stem Cell 2014, 14(3):342-356.

71. Sun B, Dong O, Ye Q, Sun H, Jia H, Zhu X, Liu D, Chen J, Xue Q, Zhou H: Lentiviral-mediated miRNA against osteopontin suppresses tumor growth and metastasis of human hepatocellular carcinoma. Hepatology 2008, 48(6):1834-1842.

72. Steinman L: A molecular trio in relapse and remission in multiple sclerosis. Nat Rev Immunol 2009, 9(6):440-447

73. Raja R, Kale S, Thorat D, Soundararajan G, Lohite K, Mane A, Karnik S, Kundu G: Hypoxia-driven osteopontin contributes to breast tumor growth through modulation of HIF1a-mediated VEGF-dependent angiogenesis. Oncogene 2014, 33(16):2053-2064.

74. Kumar S, Sharma P, Kumar D, Chakraborty G, Gorain M, Kundu GC: Functional characterization of stromal osteopontin in melanoma progression and metastasis. PloS ONE 2013, 8(7):e69116.

75. Bandopadhyay M, Bulbule A, Butti R, Chakraborty G, Ghorpade P, Ghosh P, Gorain M, Kale S, Kumar D, Kumar S, Totakura KV, Roy G, Sharma P, Shetti D, Soundararajan G, Thorat D, Tomar D, Nalukurthi R, Raja R, Mishra R, Yadav AS, Kundu GC: Osteopontin as a therapeutic target for cancer. Expert Opin Ther Targets 2014, 18(8):883-895.

76. Sharon Y, Raz Y, Cohen N, Ben-Shmuel A, Schwartz H, Geiger T, Erez N: Tumor-derived osteopontin reprograms normal mammary fibroblasts to promote inflammation and tumor growth in breast cancer. Cancer Res 2015, 75(6):963-973.

77. Koopmann J, Fedarko NS, Jain A, Maitra A, Iacobuzio-Donahue C, Rahman A, Hruban RH, Yeo CJ, Goggins M: Evaluation of osteopontin as biomarker for pancreatic adenocarcinoma. Cancer Epidemiol Biomarkers Prev 2004, 13(3):487-491.

78. Tilli TM, Thuler LC, Matos AR, Coutinho-Camillo C, Soares FA, da Silva EA, Neves AF, Goulart LR, Gimba ER: Expression analysis of osteopontin mRNA splice variants in prostate cancer and benign prostatic hyperplasia. Exp Mol Pathol 2012, 92:13-19.

79. Nakamura T, Shinriki S, Jono H, Ueda M, Nagata M, Guo J, Hayashi M, Yoshida R, Ota T, Ota K, Kawahara K, Nakagawa Y, Yamashita S, Nakayama $\mathrm{H}$, Hiraki A, Shinohara $\mathrm{M}$, Ando $\mathrm{Y}$ : Osteopontin-integrin av $\beta 3$ axis is crucial for 5-fluorouracil resistance in oral squamous cell carcinoma. FEBS Lett 2015, 589(2):231-239.

80. Liu J, Liu Q, Wan Y, Zhao Z, Yu H, Luo H, Tang Z: Osteopontin promotes the progression of gastric cancer through the NF-kappaB pathway regulated by the MAPK and PI3K. Int J Oncol 2014, 45(1):282-290.

81. Matsuura M, Suzuki T, Saito T: Osteopontin is a new target molecule for ovarian clear cell carcinoma therapy. Cancer Sci 2010, 101(8):1828-1833.

82. Srungaram P, Rule JA, Yuan HJ, Reimold A, Dahl B, Sanders C, Lee WM: Plasma osteopontin in acute liver failure. Cytokine 2015, 73:270-276

83. Sun B, Li Y, Zhang Z, You J, Wang C: Osteopontin combined with CD44v6, a novel prognostic biomarker in non-small cell lung cancer undergoing curative resection. Ann Thorac Surg 2013, 96(6):1943-1951.

84. Zhu W, Guo L, Zhang B, Lou L, Lin Z, Zhu X, Ren N, Dong O, Ye O, Oin L: Combination of osteopontin with peritumoral infiltrating macrophages is associated with poor prognosis of early-stage hepatocellular carcinoma after curative resection. Ann Surg Oncol 2014, 21(4):1304-1313.

85. Ramchandani D, Weber GF: Interactions between osteopontin and vascular endothelial growth factor: implications for cancer. BBA-Reviews on Cancer 2015, 1855(2):202-222.

86. Chang-Ni Lin, Chih-Jung Wang, Ying-Jui Chao, Ming-Derg Lai, Yan-Shen Shan: The significance of the co-existence of osteopontin and tumor-associated macrophages in gastric cancer progression. BMC Cancer 2015, 15(1):1.

87. Lan $\mathrm{Z}, \mathrm{Fu} \mathrm{D}, \mathrm{Yu} \mathrm{X}, \mathrm{Xi}$ M: Diagnostic values of osteopontin combined with CA125 for ovarian cancer: a meta-analysis. Fam Cancer 2016, 15(2): 221-230.

88. Wu Y, Denhardt DT, Rittling SR: Osteopontin is required for full expression of the transformed phenotype by the ras oncogene. Br J Cancer 2000, 83(2):156-163

89. Nemoto H, Rittling SR, Yoshitake H, Furuya $\mathrm{K}$, Amagasa T, Tsuji K, Nifuji A, Denhardt DT, Noda M: Osteopontin deficiency reduces experimental tumor cell metastasis to bone and soft tissues. J Bone Miner Res 2001, 16(4):652-659.

90. Wu XL, Lin KJ, Bai AP, Wang WX, Meng XK, Su XL, Hou MX, Dong PD, Zhang JJ, Wang ZY, Shi L: Osteopontin knockdown suppresses the growth and angiogenesis of colon cancer cells. World J Gastroenterol 2014, 20(30):10440-10448

91. Yang L, Zhao W, Zuo WS, Wei L, Song XR, Wang XW, Zheng G, Zheng MZ: Silencing of osteopontin promotes the radiosensitivity of breast cancer cells by reducing the expression of hypoxia inducible factor 1 and vascular endothelial growth factor. Chin Med J (Engl) 2012, 125(2):293-299. 
92. Mi Z, Bhattacharya SD, Kim VM, Guo H, Talbot LJ, Kuo PC: Osteopontin promotes CCL5-mesenchymal stromal cell-mediated breast cancer metastasis. Carcinogenesis 2011, 32(4):477-487.

93. Mi Z, Guo H, Wai PY, Gao C, Kuo PC: Integrin-linked kinase regulates osteopontin-dependent MMP-2 and uPA expression to convey metastatic function in murine mammary epithelial cancer cells. Carcinogenesis 2006, 27(6):1134-1145.

94. Kumar S, S Patil H, Sharma P, Kumar D, Dasari S, G Puranik V, V Thulasiram H, C Kundu G: Andrographolide inhibits osteopontin expression and breast tumor growth through down regulation of PI3 kinase/Akt signaling pathway. Curr Mol Med 2012, 12(8):952-966.

95. Mi Z, Guo H, Russell MB, Liu Y, Sullenger BA, Kuo PC: RNA aptamer blockade of osteopontin inhibits growth and metastasis of MDA-MB231 breast cancer cells. Mol Ther 2009, 17(1):153-161.

96. Rupaimoole R, Slack FJ: MicroRNA therapeutics: towards a new era for the management of cancer and other diseases. Nat Rev Drug Discov 2017, 16(3):203-222.

97. Shevde LA, Metge BJ, Mitra A, Xi Y, Ju J, King JA, Samant RS: Spheroid-forming subpopulation of breast cancer cells demonstrates vasculogenic mimicry via hsa-miR-299-5p regulated de novo expression of osteopontin. J Cell Mol Med 2010, 14(6b):1693-1706.

98. Bhattacharya SD, Garrison J, Guo H, Mi Z, Markovic J, Kim VM, Kuo PC: Micro-RNA-181a regulates osteopontin-dependent metastatic function in hepatocellular cancer cell lines. Surgery 2010, 148(2):291-297.

99. Petrocca F, Lieberman J: Micromanipulating cancer: microRNA-based therapeutics? RNA Biology 2009, 6(3):335-340.

100. Cao D, Li Z, Jiang X, Lum YL, Khin E, Lee NP, Wu G, Luk JM: Osteopontin as potential biomarker and therapeutic target in gastric and liver cancers. World J Gastroenterol 2012, 18(30):3923-3930.

101. Tu M, Li Y, Zeng C, Deng Z, Gao S, Xiao W, Luo W, Jiang W, Li L, Lei G: MicroRNA-127-5p regulates osteopontin expression and osteopontin-mediated proliferation of human chondrocytes. Sci Rep 2016, 6:25032. 